\title{
Exposure-response analysis of risk of respiratory disease associated with occupational exposure to chrysotile asbestos
}

National Institute for and Health (NIOSH), Cincinnati, Ohio 45226, USA

L Stayner

R Smith

J Bailer

$S$ Gilbert

K Steenland

R Lemen

Department of Mathematics and Statistics, Miami University, Oxford, Ohio 45056, USA J Bailer

Division of Occupational and Environmental Medicine, Duke University Medical Center, Durham, North Carolina 27710, USA

J Dement

National Institute for Environmental Health Sciences, Research Triangle Park, North Carolina, USA D Brown

Correspondence to: Dr L Stayner, Centers for Disease Control, National Institute for Occupational Safety and Health, Robert A Taff Laboratories, 4676

Columbia Parkway,

Cincinnati, Ohio

45226-1998, USA.

Accepted 26 February 1997

Leslie Stayner, Randall Smith, John Bailer, Stephen Gilbert, Kyle Steenland, John Dement, David Brown, Richard Lemen

\begin{abstract}
Objectives-To evaluate alternative models and estimate risk of mortality from lung cancer and asbestosis after occupational exposure to chrysotile asbestos.

Methods-Data were used from a recent update of a cohort mortality study of workers in a South Carolina textile factory. Alternative exposure-response models were evaluated with Poisson regression. A model designed to evaluate evidence of a threshold response was also fitted. Lifetime risks of lung cancer and asbestosis were estimated with an actuarial approach that accounts for competing causes of death.

Results-A highly significant exposureresponse relation was found for both lung cancer and asbestosis. The exposureresponse relation for lung cancer seemed to be linear on a multiplicative scale, which is consistent with previous analyses of lung cancer and exposure to asbestos. In contrast, the exposure-response relation for asbestosis seemed to be nonlinear on a multiplicative scale in this analysis. There was no significant evidence for a threshold in models of either the lung cancer or asbestosis. The excess lifetime risk for white men exposed for $\mathbf{4 5}$ years at the recently revised OSHA standard of $0.1 \mathrm{fibre} / \mathrm{ml}$ was predicted to be about 5/1000 for lung cancer, and 2/1000 for asbestosis.

Conclusions-This study confirms the findings from previous investigations of a strong exposure-response relation between exposure to chrysotile asbestos and mortality from lung cancer, and asbestosis. The risk estimates for lung cancer derived from this analysis are higher than those derived from other populations exposed to chrysotile asbestos. Possible reasons for this discrepancy are discussed.
\end{abstract}

(Occup Environ Med 1997;54:646-652)

Keywords: chrysotile asbestos; risk assessment; epidemiology

There has been considerable discussion in the scientific literature about the significance of the risks associated with exposure to chrysotile asbestos. $^{12}$ This debate is of importance to public health, as chrysotile is the most often used asbestos fibre in production worldwide ${ }^{3}$ and is also the main source of exposure resulting from efforts to remove asbestos in the United States today.

There are only two industrial cohorts that have relatively pure exposures to chrysotile asbestos and supply sufficiently high quality data for exposure-response analysis. These are the studies of Quebec miners and millers ${ }^{4}$ and a National Institute for Occupational Safety Health (NIOSH) study of South Carolina textile workers. ${ }^{5}$ Both studies have been used by the Occupational Safety and Health Administration (OSHA) ${ }^{6}$ and the Environmental Protection Agency (EPA) ${ }^{7}$ in their quantitative risk assessments for asbestos.

The NIOSH cohort of chrysotile asbestos textile workers was recently updated to include an additional 15 years of observation and expanded to include women and non-white people as well as white male workers. ${ }^{5}$ Our paper presents an exposure-response analysis and risk estimates for lung cancer and non-malignant mortality from respiratory disease based on the most recent update of the mortality of the study of the NIOSH cohort of textile workers.

\section{Material and methods}

STUDY POPULATION

A detailed description of the design of the NIOSH cohort of chrysotile asbestos textile workers may be found in several previously published papers. ${ }^{599}$ Briefly, the plant was located in South Carolina and began producing asbestos products in 1896. Chrysotile asbestos received from Quebec, British Columbia, and Zimbabwe was the only type of asbestos processed as raw fibre. Crocidolite yarn was used in extremely small quantities from the 1950s until 1975 (about 2000 pounds), and the exposures resulting from this process are thought to have been low and limited to specific jobs. ${ }^{58}$

The original analysis was restricted to include white male workers $(n=1247)$ employed in the textile production operations for at least one month between 1 January 1940 and 31 December 1975. In the most recent publication, ${ }^{5}$ this cohort was expanded to include non-white men $(n=546)$, and white women $(n=1229)$ who met the same employment requirements. Follow up of this cohort for vital status was extended up to 31 December 1990 . The analyses presented in this paper 
include all of the sex and race groups from this study including non-white women $(n=19)$.

One of the strengths of this study is the relatively high quality of information on exposure that was available for estimating historic occupational exposure to asbestos. Exposure levels to chrysotile (fibres $>5 \mu \mathrm{m} / \mathrm{ml}$ ) by areas of the plant (department and operations), specific jobs, and calendar years have been previously developed ${ }^{8}$ and were used with information on work history to estimate individual exposures for the present analysis. Changes in processes and controls were taken into consideration in deriving historical exposure estimates. Cumulative exposure to asbestos, which is the product of duration and intensity of exposure to asbestos, was the exposure metric used in the statistical analyses described below.

\section{STATISTICAL ANALYSES}

Exposure-response analyses were conducted for cancer of the trachea, bronchus, and lung (henceforth collectively referred to as lung cancer), and for asbestosis and pneumoconiosis (henceforth collectively referred to as asbestosis). The underlying cause of death was used to define the response for lung cancer (9th revision of the international classification of diseases $($ ICD-9) $=162$ ). For asbestosis, a multiple cause of death approach ${ }^{10}$ was used in which all of the fields of the death certificate were considered. This approach was used because asbestosis is often not listed as the underlying cause of death on death certificates. Also, the definition of asbestosis was broadened to include deaths from pneumoconiosis (ICD-9 =505) as well as from asbestosis (ICD$9=501$ ), as the more general term pneumoconiosis may have been used instead of asbestosis on death certificates. Based on these definitions, 126 cases of lung cancer and 45 cases of asbestosis (only one of which was pneumoconiosis) were available for this analysis.

The person-years and deaths stratified by the covariates for the Poisson regression analysis were generated with the NIOSH life table analysis system. ${ }^{11}$ Person-years for this analysis were counted from the time when a person met the study requirements until the time when they were either lost to follow up, died, or reached the end of the study. For lung cancer, the person-years and observed deaths were restricted to only include those with at least 15 years since the date of first exposure (latency).

The person-years and observed deaths were partitioned into 20 cumulative asbestos categories, which had roughly equal numbers of deaths (all causes). Cumulative exposure was modelled as a continuous variable from the midpoints of each exposure category. These extensive categories permitted a detailed exploration of the shape of the exposure-response relation.

Poisson regression models ${ }^{12}$ were used to analyse the exposure-response relation between exposure to chrysotile asbestos and mortality from respiratory disease with the observed deaths and person-years generated by the NIOSH life table analysis system. Different potential model forms were evaluated, which include functions that have been previously proposed for the analysis of epidemiological cohort data. ${ }^{13}$ Together these models are capable of reflecting a wide range of possible exposure-response patterns including linear, sublinear, and supralinear.

Models in which the effect of exposure either multiplied (multiplicative models) or added (additive models) to the background hazard rate were evaluated. These models may be represented mathematically as:

Multiplicative: $\lambda=\lambda_{0} \times \mathrm{f}(\mathrm{E})$

Additive: $\quad \lambda=\lambda_{0}+\mathrm{f}(\mathrm{E})$

where $\lambda$ is the predicted incidence rate, $f(E)$ is a function of cumulative exposure to asbestos (E) in fibre-year $/ \mathrm{ml}$, and $\lambda_{0}$ is the background incidence which is a function of age, sex, race, and calendar time.

The background incidences were modelled as a $\log (\ln )$ linear function of the following covariates: age (continuous), sex, race (white $v$ non-white), and calendar time (1940-69, 1970-9, 1980-90)^, which may be represented mathematically as:

$\ln \left(\lambda_{0}\right)=\beta_{0}+\beta_{1} \mathrm{I}($ sex $=$ female $)+\beta_{2} \mathrm{I}($ race $=$ white $)$ $+\beta_{3}$ (age) $+\beta_{4} \mathrm{I}\left(\right.$ year=1970-9) $+\beta_{5} \mathrm{I}($ year $=$ 1980-9)

where $\beta_{0}$ is the intercept, $\beta_{1}, \beta_{2}, \beta_{3}, \beta_{4}$, and $\beta_{5}$ are the parameters associated with the effects of sex, race, age, and calendar year. The I()s are indicator variables ( 0 or 1$)$ for the categorical levels of sex, race, and calendar year.

Evaluation of the additive model (1b) was limited to a simple linear function for modelling the exposure-response relation, as these models were generally found to fit the data far worse than the multiplicative models. This simple function may be represented mathematically as:

$f(E)=\beta_{E} E$

Different parametric functions were evaluated for modelling the exposure-response relation for the multiplicative models including the following forms:

Log-linear:

$$
\begin{aligned}
& f(E)=\exp \left(\beta_{E} E\right) \text { or } \ln (f(E))=\beta_{E} E \\
& \text { Log-quadratic: } \\
& f(E)=\exp \left(\beta_{E 1} E+\beta_{E 2} E^{2}\right) \\
& \text { Additive relative rate: } \\
& f(E)=1+\beta_{E} E \\
& \text { Power: } \\
& f(E)=\exp \left(\beta_{E} \ln (E+\alpha)\right)
\end{aligned}
$$

where $\beta_{\mathrm{E}}$ (and $\beta_{\mathrm{E} 1}+\beta_{\mathrm{E} 2}$ ) are the parameters associated with exposure to asbestos $(\mathrm{E})$, and $\alpha$ is a constant that is added to the exposure for the power model. The value of $\alpha$ was solved by iteratively fitting the model with different values of $\alpha$ until the deviance of the model was

* A broad category was used for the first period of study (1940-69) because there were relatively few deaths from lung cancer or asbestosis during the early period of the study. This earliest category was used as a control category, which is represented by the intercept. 
minimised (note: for this model the background hazard rate is $\lambda_{0} \times \alpha^{\beta E}$ ).

An informal statistical evaluation of goodness of fit was performed by comparing the deviances of these models (technically not all of these models are nested, and thus, a formal comparison was not always possible). The models with the smallest deviance were considered to be the best fitting models. Also, these models were graphically evaluated by comparing the fit of these parametric models with a categorical model, and a cubic spline model. ${ }^{14}$

For the categorical model, the number of exposure categories was reduced to 10 from 20 by simply combining adjacent categories-for example, categories 1 and 2, 3 and 4 etc-to improve the stability of the estimates of the rates. The categorical exposure function may be represented mathematically as:

Categorical:

$$
f(E)=\sum_{k=2}^{10}\left(\left(\beta_{k} I(\text { exposure category }=k)\right)\right)
$$

where: $\beta_{k}$ are the parameters and I() are indicator variables for the $\mathrm{k}=9$ highest exposure categories, and the lowest exposure category is used as the control group.

The restricted cubic spline is a model that makes flexible assumptions about the form of the exposure-response relation based on a few unknown parameters. Essentially, the approach consists of fitting cubic polynomials within defined intervals of the exposure variable that are restricted to be smooth at the cut off points (or knots) which separate the intervals. For the restricted cubic spline model four knots were used at the 5th (p05), 25th (p25), 75th (p75), and 95th (p95) percentiles of the cumulative exposure to asbestos distribution. This model may be represented mathematically as:

Restricted cubic spline:

$f(E)=\exp \left(\beta_{1} E_{1}+\beta_{2} E_{2},+\beta_{3} E_{3}\right)$

Table 1 Comparison of results of exposure to chrysotile asbestos from fitting alternative Poisson regression models to the mortalities for lung cancer

\begin{tabular}{|c|c|c|c|}
\hline \multirow[b]{2}{*}{ Model form (number in text) } & \multicolumn{2}{|l|}{ Results for asbestos } & \multirow[b]{2}{*}{ Model deviance } \\
\hline & Parameter estimate & $S E$ & \\
\hline Baseline model $(2)^{\star}$ & - & - & $716.8(\mathrm{df}=2429)$ \\
\hline $\begin{array}{l}\text { Additive model (3a) } \\
\text { Multiplicative models: }\end{array}$ & $4.79 \mathrm{e}-08$ & $1.24 \mathrm{e}-08$ & $701.3(\mathrm{df}=2428)$ \\
\hline Log linear(3b) & $7.21 \mathrm{e}-03$ & $1.13 \mathrm{e}-03$ & $685.0(\mathrm{df}=2428)$ \\
\hline Log quadratic(3c) & & & $676.9(\mathrm{df}=2427)$ \\
\hline $\boldsymbol{\beta}_{1}$ & $1.72 \mathrm{e}-02$ & $3.62 \mathrm{e}-03$ & \\
\hline$\beta_{2}$ & $-4.36 e-05$ & $1.55 \mathrm{e}-05$ & \\
\hline Additive relative rate( $3 d$ ) & $2.19 \mathrm{e}-02$ & $7.00 \mathrm{e}-03$ & $679.0(\mathrm{df}=2428)$ \\
\hline Power(3e) & & & $678.1(\mathrm{df}=2427)$ \\
\hline$\alpha$ & 6.10 & & \\
\hline$\beta$ & $4.86 \mathrm{e}-01$ & $7.64 \mathrm{e}-02$ & \\
\hline Spline(3f) & & & $678.5(\mathrm{df}=2426)$ \\
\hline$\beta_{1}$ & $2.68 \mathrm{e}-02$ & $2.34 \mathrm{e}-02$ & \\
\hline$\beta_{2}$ & -0.0001 & 0.0001 & \\
\hline$\beta_{3}$ & 0.0001 & 0.0001 & \\
\hline Categorical(3g) & & & $673.5(\mathrm{df}=2420)$ \\
\hline $0.81 \leqslant X<1.64$ & -0.05 & 0.54 & \\
\hline $1.64 \leqslant X<2.74$ & 0.21 & 0.54 & \\
\hline $2.74 \leqslant X<4.93$ & 0.70 & 0.46 & \\
\hline $4.93 \leqslant X<8.76$ & 0.70 & 0.48 & \\
\hline $8.76 \leqslant X<17.80$ & 0.73 & 0.49 & \\
\hline $17.80 \leqslant X<38.33$ & 0.58 & 0.51 & \\
\hline $38.33 \leqslant \mathrm{X}<79.40$ & 1.19 & 0.45 & \\
\hline $79.40 \leqslant X<136.89$ & 1.42 & 0.44 & \\
\hline$X \geqslant 136.89$ & 2.02 & 0.45 & \\
\hline
\end{tabular}

$\star$ The baseline model includes the effect of age, calendar year, race, and sex. The other models also include these terms as well as terms representing asbestos exposure. where: $E_{1}=$ cumulative exposure to asbestos, and $E_{2}$ and $E_{3}$ are functions of cumulative exposure as described by Herndon and Harrel. ${ }^{14}$

From the statistical and graphical evaluations, a final functional form was chosen for modelling the relation between exposure to asbestos and the response variables. Further evaluation of potential interactions between the exposure and the other covariates, and of higher order exposure terms (quadratic and cubic) were evaluated before arriving at a final model for risk assessment purposes.

Finally, a "threshold" model ${ }^{15}$ was considered to assess whether there was evidence that exposures below a certain level were equivalent to 0 exposure - that is, a threshold was present. This model may be represented mathematically as:

Threshold:

$f(E)=\exp \left(\beta_{e}(E-\Theta)\right)$ if $E>\Theta f(E)=1$ if $E \leqslant \Theta$

where $\Theta$ is a threshold parameter that was solved by iteratively fitting the model and setting the parameter to the midpoint of each of the 20 exposure categories until the deviance was minimised.

All of the models were fitted with the Epicure program.

PREDICTION OF WORKING LIFETIME RISKS

Estimates of excess lifetime risk of dying from lung cancer and asbestosis were developed for varying levels of exposure to chrysotile asbestos based upon an actuarial method that was developed in a risk analysis of radon exposures (BEIR IV 1988), which accounts for the influence of competing risks. It was assumed for this estimation procedure that workers were exposed to a constant asbestos concentration for 45 years between the ages of 20 and 65 . The annual risks were accumulated up to age 90 . Age specific background rates for lung cancer and asbestosis were estimated from the final Poisson regression models developed for these outcomes. Age specific background rates for competing causes of death were estimated by applying life table methods to the study cohort.

\section{Results}

\section{POISSON REGRESSION ANALYSES}

Lung cancer

Table 1 and figure 1 shows the results from fitting the various Poisson regression models described in the methods section. Exposure was a highly significant predictor $(P<0.001)$ of lung cancer mortality in all of the models evaluated. The simple linear model (model 3a) provided a poor fit to the data when contrasted with the multiplicative models in table 1 . Between the two multiplicative models (model $3 \mathrm{~b}$, and $3 \mathrm{~d}$ ) that used only one parameter for exposure to asbestos, the additive relative rate model (model 3d) gave the best fit to the data based on the criteria of minimum deviance. The deviance of the models was not appreciably improved by the models with additional parameters for exposure to asbestos such as the quadratic model (model 3c) or the power model (model 3e). 


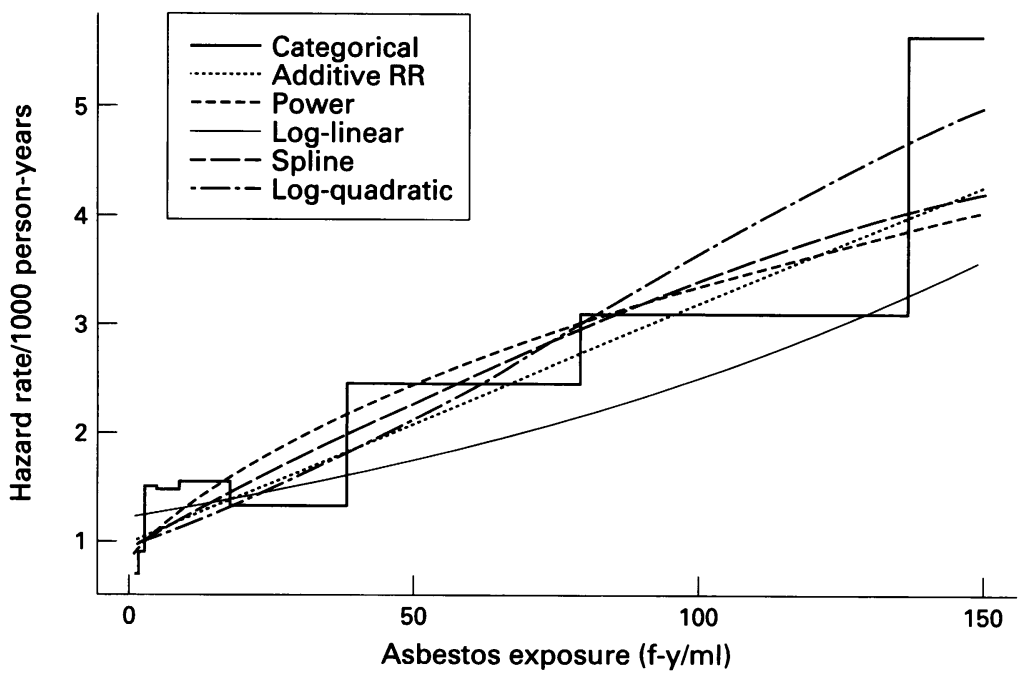

Figure 1 Lung cancer mortalities as a function of cumulative exposure to asbestos predicted by alternative models for white men aged 50 in 1940-69.

Examination of figure 1 essentially confirms the impressions based on examination of deviances. The curve for the additive relative rate model provides similar estimates of the rate as the spline model, and is reasonably consistent with the rate estimates from the categorical model. The quadratic and power models also seem to provide similar estimates, whereas the log linear model seems to produce low estimates of the hazard rate.

Based on this evaluation the additive relative rate model (model 3c) was chosen as the basis for further analysis. There was no indication of a significant interaction between any of the covariates (age, race, sex, or year) and exposure to asbestos, or of a need for higher order terms (quadratic or cubic) to represent exposure. An evaluation of interaction with time since first exposure (latency) and exposure to asbestos was performed by fitting a model with separate slopes for exposure with 15 to $<30,30$ to $<40$ and $>40$ years of latency. This model was found to fit the data significantly $\left(\chi^{2}=6.5\right.$, $\mathrm{df}=2, \mathrm{P}=0.04$ ) better than the simpler additive relative rate model and was chosen as the final model for predicting lifetime risks. Table 2 show the parameter estimates and SEs from this final model. The goodness of fit of this model was judged to be good based on the fact that the model deviance was much smaller than the numbers of degrees of freedom. Based on this model, the relative rate per unit of cumulative exposure to asbestos (X) from this model would be $(1+0.022(\mathrm{X}))$ with $15-29$ years of latency, $(1+0.037(\mathrm{X}))$ with $30-39$ years of latency, and $(1+0.011(\mathrm{X}))$ with $\geqslant 40$ years of

Table 2 Parameter estimates and SEs from the best fitting model for lung cancer mortality

\begin{tabular}{lcl}
\hline Model parameters & Parameter estimates & $S E$ \\
\hline Intercept & -16.51 & 0.56 \\
Sex (female) & -0.95 & 0.20 \\
Race (non-white) & -1.05 & 0.29 \\
Year (1970-9) & -0.06 & 0.30 \\
Year (1980-90) & 0.47 & 0.30 \\
Age & 0.07 & 0.01 \\
Asbestos $\times$ latency (15-29) & 0.022 & 0.012 \\
Asbestos $\times$ latency $(30-39)$ & 0.037 & 0.012 \\
Asbestos $\times$ latency $(240)$ & 0.011 & 0.006
\end{tabular}

Model deviance $=672.5 ; \mathrm{df}=2426$. latency. For example, for 45 years of exposure to $0.1 \mathrm{fibre} / \mathrm{ml}$ the predicted relative rate would be 1.10 for workers with 15-29 years of latency. The deviance of the threshold model (model $3 \mathrm{~h}$ ), relative to a model without the threshold parameter (model 3b), was not reduced regardless of what value of $\Theta$ was chosen. Hence the results from this model did not provide any support for the existence of a threshold type response for lung cancer.

\section{AsBestosis}

Table 3 shows the results from fitting the various Poisson regression models described in the methods section for asbestosis (fig 2). The exposure-response relation was found to be highly significant $(P<0.001)$ in all of the multiplicative models evaluated. The additive model failed to converge unless the baseline rate function was left out of the model, and the additive relative rate model completely failed to converge. Adding a quadratic term (model 3c) significantly improved the fit of the log linear model (model 3b). Based on the deviance, the power model (model $3 \mathrm{e}$ ) was found to provide the best fit to the data of all of the two exposure parameter models. The deviance of the power model was nearly equivalent to the spline model with more parameters, close to the categorical model with full parameters, and represented a large improvement relative to the models with a single parameter for exposure to asbestos.

These statistical impressions of goodness of fit are reasonably consistent (fig 2 ). The quadratic and power models produced similar estimates of the hazard rate, which seem to be consistent with the categorical model. The spline model produced somewhat higher estimates, and the log linear model lower estimates, particularly at high exposure levels $(>100$ fibre/ml).

Based on this analysis, the power model was selected as the most appropriate model for further evaluation. There was no evidence of a significant interaction in the power model between exposure to asbestos and any of the other covariates included in the baseline function. Table 4 shows the parameter estimates and SEs from the final power model. The goodness of fit of this model was judged to be good based on the fact that the model deviance was much smaller than the numbers of degrees of freedom. Based on this model, the relative rate for cumulative exposure (X) would be equal to $\left((X+0.5)^{1.3} /(0.5)^{1.3}\right)$. For example, for 45 years of exposure to $0.1 \mathrm{fibre} / \mathrm{ml}$ the relative rate would be 19.95 .

The fit of the threshold model (model 3h), relative to a model without the threshold parameter, was not improved regardless of what value of $\Theta$ was chosen. Hence the results from this model did not provide any support for the existence of a threshold type response for this outcome.

\section{PREDICTION OF LIFETIME RISKS}

Table 5 shows the predicted lifetime excess risks of lung cancer and asbestosis assuming 45 years of exposure to varying exposures of 
Table 3 Comparison of results of exposure to chrysotile asbestos from fitting alternative Poisson regression models to the mortalities for asbestosis

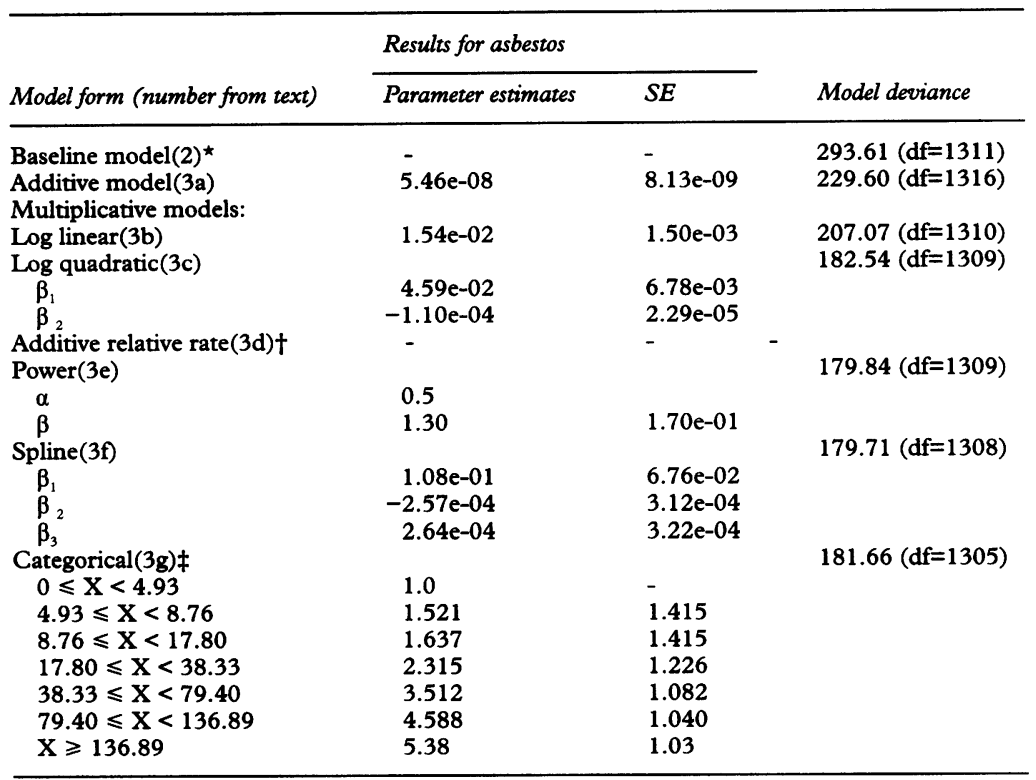

« The baseline model includes the effect of age, calendar year, race, and sex. The other models also include these terms as well as terms representing asbestos exposure except for the linear model, which would not converge with these terms included in the model.

t The model failed to converge.

¥ Fitting this model required that the number of exposure categories be reduced to seven because the first three categories had no deaths.

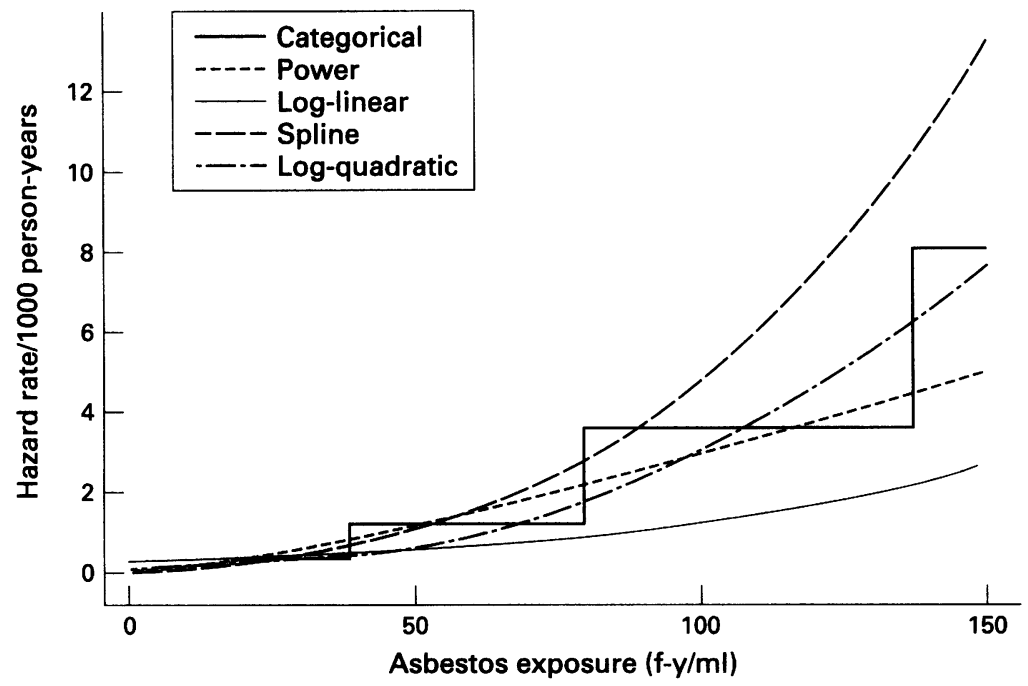

Figure 2 Asbestosis mortalities as a function of cumulative exposure to asbestos predicted by alternative models for white men, aged 50 in 1940-69.

chrysotile asbestos, based on the final models for lung cancer (table 2), and asbestosis (table 4). The risks vary by sex and race because of differences in the background rates used in the models. The predicted risks for asbestosis are less than those for lung cancer at low exposure levels-for example, <0.5. At higher exposures levels this pattern is reversed with the predicted risks for asbestosis being higher than those for lung cancer For example, at the recently revised OSHA standard of 0.1 fibre $/ \mathrm{ml}$ the predicted lifetime excess risk for white men is about $5 / 1000$ for lung cancer and $2 / 1000$ for asbestosis. However, at $3.0 \mathrm{fibre} / \mathrm{ml}$ the predicted lifetime excess risk for white men is about $112 / 1000$ for lung cancer and 163/1000 for asbestosis. This change in the relative pattern in risk of lung cancer and asbestosis is
Table 4 Parameter estimates and SEs from the best fitting model for asbestosis mortality

\begin{tabular}{lll}
\hline Model parameters & Parameter estimates & $S E$ \\
\hline Intercept & -0.21 & 0.99 \\
Sex (F) & -1.38 & 0.41 \\
Race (non-white) & -1.17 & 0.42 \\
Year (1970-9) & 0.03 & 0.37 \\
Year (1980-90) & -0.58 & 0.46 \\
Age & 0.07 & 0.01 \\
Cumulative asbestos: & & \\
$\quad \alpha$ & 0.50 & \\
$\beta$ & 1.30 & 0.17 \\
\hline Model deviance=179.836; df $=1310$. &
\end{tabular}

explained by the non-linear exposure-response relation for asbestosis.

\section{COMPARISON WITH PREVIOUS ANALYSES FOR}

LUNG CANCER

The exposure-response relation between exposure to asbestos and mortality from lung cancer, which formed the basis for the lung cancer risk estimates reported in this paper, may be compared with those from previous analyses. The slope of 0.021 ( $95 \%$ confidence interval $(95 \% \mathrm{CI})=0.008$ to 0.036$)$ from the additive relative rate model (table 2 ) was similar to the slope reported in a previous paper by Dement et al. ${ }^{5}$ This was not entirely surprising as both analyses were based on the same data base, although different analytical methods were used. However, the estimates of slope derived from this cohort are higher than those based on other studies. In 1986 OSHA $^{6}$ used a slope of 0.01 from an additive relative rate model (model 3d) for its assessment of risk from asbestos, which is about half as large as the estimate in this paper. This slope was based on a geometric mean of the slopes from studies of manufacturing and application of asbestos insulation. The differences between our findings and those from studies of Quebec chrysotile miners and millers ${ }^{4}{ }^{17}$ are even more dramatic. The slope from an additive relative rate model from the Quebec study ${ }^{17}$ was approximately 0.0005 per fibre/ml-year ( $95 \%$ CI 0.0002 to 0.0008 ), which is over an order of magnitude lower than the slope from the present analysis. (This study reported their findings in mpcf-year, not fibre/ml-year. An approximate conversion factor of $3 \mathrm{fibre} / \mathrm{ml}$ year for each mpcf-year was used to calculate the slope. A 95\% CI for this slope was estimated with the reported SE and a normal approximation.)

\section{Discussion}

The results from these analyses clearly show a strong exposure-response relation between exposure to chrysotile and mortality from asbestosis and lung cancer. Of course, these findings were to be expected based on previous studies of this and other cohorts of workers exposed to chrysotile asbestos. However, some have suggested that exposure to chrysotile asbestos may not be hazardous, ${ }^{18}$ and our findings are clearly inconsistent with that view.

The exposure-response relation for lung cancer seemed to be linear on a multiplicative scale. This is consistent with previous analyses of lung cancer and exposure to asbestos. ${ }^{19}$ In 
Table 5 Predicted excess lifetime risks of lung cancer and asbestosis assuming 45 years of varying time weighted average (TWA) exposure levels of chrysotile asbestos

\begin{tabular}{lllll}
\hline \multirow{4}{*}{ Disease } & \multicolumn{4}{l}{ Lifetime excess risk estimates * } \\
\cline { 3 - 5 } & $T W A\left(\right.$ fibres $\left./ m^{3}\right)$ & White men & White women & Non-white men \\
\hline \multirow{2}{*}{ Lung cancer } & 0.1 & $5 \mathrm{e}-03$ & $3 \mathrm{e}-03$ & $2 \mathrm{e}-03$ \\
& 0.3 & $1 \mathrm{e}-02$ & $1 \mathrm{e}-02$ & $5 \mathrm{e}-02$ \\
& 0.5 & $2 \mathrm{e}-02$ & $2 \mathrm{e}-02$ & $9 \mathrm{e}-02$ \\
& 0.7 & $3 \mathrm{e}-02$ & $2 \mathrm{e}-02$ & $1 \mathrm{e}-02$ \\
& 0.9 & $4 \mathrm{e}-02$ & $3 \mathrm{e}-02$ & $2 \mathrm{e}-02$ \\
& 1.0 & $4 \mathrm{e}-02$ & $3 \mathrm{e}-02$ & $2 \mathrm{e}-02$ \\
Asbestosis & $8 \mathrm{e}-02$ & $6 \mathrm{e}-02$ & $4 \mathrm{e}-02$ \\
& 2.0 & $1 \mathrm{e}-01$ & $9 \mathrm{e}-02$ & $5 \mathrm{e}-02$ \\
& 3.0 & $2 \mathrm{e}-03$ & $1 \mathrm{e}-03$ & $1 \mathrm{e}-03$ \\
& 0.1 & $9 \mathrm{e}-03$ & $4 \mathrm{e}-03$ & $3 \mathrm{e}-03$ \\
& 0.3 & $2 \mathrm{e}-02$ & $8 \mathrm{e}-03$ & $6 \mathrm{e}-03$ \\
& 0.5 & $3 \mathrm{e}-02$ & $1 \mathrm{e}-02$ & $9 \mathrm{e}-03$ \\
& 0.7 & $4 \mathrm{e}-02$ & $2 \mathrm{e}-02$ & $1 \mathrm{e}-02$ \\
& 0.9 & $4 \mathrm{e}-02$ & $2 \mathrm{e}-02$ & $1 \mathrm{e}-02$ \\
& 1.0 & $1 \mathrm{e}-01$ & $5 \mathrm{e}-02$ & $4 \mathrm{e}-02$ \\
& 2.0 & $2 \mathrm{e}-01$ & $8 \mathrm{e}-02$ & $6 \mathrm{e}-02$ \\
\hline
\end{tabular}

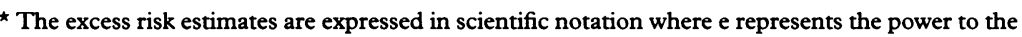
base 10 that the number should be multiplied by. For example, the excess lifetime risk of lung cancer for white men at 0.1 fibres $/ \mathrm{m}^{3}$ is $5 \mathrm{e}-03$, which is equivalent to $5 / 1000$ workers.

contrast, the exposure-response relation for asbestosis seemed to be non-linear on a multiplicative scale in this analysis. This relation was in fact sublinear, which implies that the risk of asbestosis drops off more rapidly with reductions in exposure than does the risk of lung cancer.

There was absolutely no significant evidence for a threshold in either the lung cancer or asbestosis models. The fit of these models was in fact found to be maximised when the threshold parameter was set to zero. Thus the results from this analysis fail to provide any support for arguments that have been made for a threshold for the effects of chrysotile asbestos on risks of lung cancer and asbestosis. ${ }^{20}$

Based on this analysis, the predictions of risk for lung cancer are somewhat higher than the predictions for asbestosis at current exposure levels. The excess lifetime risk for white men exposed for 45 years at the recently revised OSHA standard of $0.1 \mathrm{fibre} / \mathrm{ml}$ was predicted to be about $5 / 1000$ for lung cancer, and $2 / 1000$ for asbestosis. It was not possible to model rates for mesothelioma based on this cohort, because there were too few cases. However, given the fact that there were over 60 excess cases of lung cancers and only three of mesothelioma, it is obvious that the risk of mesothelioma is far less than that of lung cancer for this population. Overall, these risk estimates indicate that it may be appropriate to control exposure to chrysotile asbestos even below the current OSHA standard if technically feasible.

There are several assumptions and sources of uncertainty underlying the predictions of risk made in this paper that must be recognised. Firstly, these epidemiological observations are based on relatively high exposure levels compared with current conditions and thus some degree of extrapolation beyond the range of the data was made to predict risks for current exposure conditions. However, this extrapolation was not as extreme as is often the case in quantitative risk assessments. The average exposure intensity (cumulative exposure/ duration) of this cohort was about $6 \mathrm{fibre} / \mathrm{ml}$ and predictions were only made for exposures as low as $0.1 \mathrm{fibre} / \mathrm{ml}$.

Secondly, as with nearly all epidemiological investigations of this nature, questions may be asked about the accuracy of exposure estimates that were used in this analysis. The quality of this information was unusually high compared with most retrospective cohort mortality studies. The exposure classifications in this study were based on over 5900 measurements and exposure conditions did not change appreciably over the time course of the study. ${ }^{8}$ There was a need to convert measurements that were based on a method that estimates millions of fibres per cubic foot (mfpcf) to the current method of fibre/ml that are $>5 \mu \mathrm{m}$ in length. It has been suggested that these conversions may introduce large errors into the risk assessment process. ${ }^{21}$ Also, it has been argued that analyses based on cumulative exposure are an oversimplification which ignore the separate effects of intensity and duration of exposure. ${ }^{4}$ Unfortunately it is difficult, if not impossible, to separate these effects in studies such as this one because of a lack of information on variations in intensity, and the ever changing exposure patterns of workers.

Thirdly, the absence of individual information on cigarette smoking habits for this entire cohort introduces some degree of uncertainty into this analysis. Information on smoking was available for a sample of the cohort which suggests that smoking habits among black men were lower, white men were similar, and white women were lower compared with the general sex and race specific population of the United States. ${ }^{5}$ However, the fact that this analysis was restricted to comparison of rates within the cohort reduces the possibility of bias due to confounding by cigarette smoking. Confounding would only be possible if cigarette smoking was associated with the potential for exposure to asbestos in this cohort, which seems unlikely. Of greater possible concern is the lack of consideration of the potential interaction between cigarette smoking and exposure to asbestos in the induction of lung cancer. ${ }^{22}$ Berry $e t$ al in a review of studies on this issue reported that non-smokers exposed to asbestos have a zero to fivefold greater relative risk of lung cancer than smokers who have an expected value of $1.8 .^{23}$ These results suggest that the interaction between smoking and asbestos may be greater than additive but less than multiplicative. In any case, the results from this analysis may be viewed as valid for a population with a similar distribution of smoking habits, but may either over or underestimate risk for other populations depending on their distribution of smoking habits.

Fourthly, there is a serious potential for disease misclassification in this study particularly for asbestosis. Death certificates are not generally regarded as a reliable source of information for asbestosis. ${ }^{24}$ This is primarily because asbestosis is often not recognised as the underlying cause of death. We have tried to minimise this problem by using a multiple cause of death approach in this analysis. However, it is likely that this approach has failed to detect all of the 
cases of asbestosis in this cohort and thus the risk of asbestosis is likely to have been underestimated. Lung cancer is generally recognised as the underlying cause of death, and thus a multiple cause of death approach was not necessary for this outcome.

Fifthly, the selection of an appropriate model is (as always) a major source of uncertainty for a risk analysis. We have evaluated many models in this paper, rather than simply assuming a linear model as in previous analyses. None the less, the choice of models was based on goodness of fit and not on knowledge of the underlying mechanism.

Probably the largest source of uncertainty relates to the suitability of these findings to be generalised to current exposure to asbestos in the workplace or elsewhere. The predictions from these analyses on risks of lung cancer were higher than previous OSHA estimates for all forms of asbestos, and substantially higher than the risk predictions based on analysis of Quebec miners. The reasons for these widely varying results are not known. Initially, it was suspected that they might be attributed to differences in tremolite contamination or errors in assessment of exposure. However, these theories were ruled out by subsequent pathology studies. $^{25}$

Another hypothesis that has been advanced is that the higher risks of lung cancer in the textile plant may be related to exposures to mineral oil. ${ }^{25}$ This hypothesis is inconsistent with the finding that mineral oils have not been shown to induce lung cancer in studies of workers exposed to machining fluids. ${ }^{26}$ Furthermore, the relation between chrysotile asbestosis and risk of lung cancer was not altered when exposure for mineral oil was controlled for in a nested case-control study of the NIOSH asbestos cohort. ${ }^{5}$

A viable hypothesis that might explain these discrepant findings is that the percentage of long fibres was higher in the asbestos textile industry in South Carolina than in the Quebec mining industries. ${ }^{5}$ It is known that long thin fibres were preferred for use in the textile industry. Also, the carding process used in the textile industry sheared the asbestos into long thin fibres. There is also substantial toxicological evidence that long thin fibres are more carcinogenic than short thick ones. ${ }^{27}$ If fibre dimensions are the explanation for these discrepant findings then it would be important to know whether the distribution of chrysotile fibre lengths and widths in current operations are more similar to those experienced historically in the NIOSH textile cohort or in the Quebec miners and millers. Until this issue is resolved, it would seem prudent to consider the estimates of risk from the NIOSH textile cohort, as well as those based on the Quebec mining and milling cohort, as relevant for predicting a range of potential risks for current industrial and remediation operations that involve chrysotile asbestos.
We acknowledge and thank Drs Richard Hornung, Jim Dedden, David Umbach, and Patricia Sullivan for their helpful reviews of this paper.

1 Mossman BT, Bigman J, Corn M, Seaton A, Gee JBL. Asbestos: scientific developments, and implications for public policy. Science 1990;24:294-301.

2 Stayner LT, Dankovic DA, Lemen RA. Occupational exposure to chrysotile asbestos and cancer risk: a review of the amphibole hypothesis. Am $\mathcal{f}$ Public Health 1996;86:179-86.

3 Pigg BJ. The uses of chrysotile asbestos. Ann Occup Hyg 1994;38:453-8.

4 McDonald JC, Liddell FDK, Dufresne A, McDonald AD. The 1891-1920 birth cohort of Quebec chrysotile miners and millers: mortality 1976-88. Br F Ind Med 1993;50: 1072-81.

5 Dement JM, Brown DP, Okun A. Follow-up study of chrysotile asbestos textile workers: cohort mortality and case-control analyses. Am $\mathcal{F}$ Ind Med 1994;26:431-47.

6 OSHA (1986). Occupational exposure to asbestos, tremolite, anthophylite, and actinolite. Federal Register 1986;51 22612-747.

7 Nicholson WJ. Airborne asbestos health assessment update. Springfield, VA: US Department of Commerce, National Technical Information Service. Final Report EPA-600-884-003F, June 1986.

8 Dement JM, Harris RL, Symons MJ, Shy CM. Exposures and mortality among chrysotile asbestos workers. Part I exposure estimates. Am $\mathcal{F}$ Ind Med 1983;4:399-419.

9 Dement JM, Harris RL, Symons MJ, Shy CM. Exposures and mortality among chrysotile asbestos workers. Part II mortality. Am ₹ Ind Med 1983;4:421-33.

10 Steenland K, Nowlin S, Ryan B, Adams S. Use of multiplecauses mortality data in epidemiologic analyses, $A m \mathcal{F} E p i$ demiol 1992;136:855-62.

11 Steenland KJ, Beaumont J, Spaeth S, Brown D, Okun A Jurcenko L, et al. New developments in the NIOSH lifetable system. F Occup Med 1990;32:1091-8.

12 Frome EL, Checkoway H. Use of Poisson regression model in estimating incidence rates and ratios. $\mathrm{Am} \mathcal{F}$ Epidemio 1985;121:309-22.

13 Breslow NE, Day NE. Statistical methods in cancer research. Vol 2. The design and analysis of cohort studies. Lyon:International Agency for Research on Cancer, 1987.

14 Herndon JE, Harrell FE. The restricted cubic spline as baseline hazard in the proportional hazards model with step function time-dependent covariables. Stat Med 1995; 14:2119-29.

15 Ulm KW. Threshold models in occupational epidemiology. Mathematical Computer Modeling 1990;14:649-52.

16 Committee on the Biological Effects of Ionizing Radiation, Board of Radiation Effects Research, Commision on Life Sciences, National Research Council. Biological effects of ionizing radiation (BEIR) IV. Health risks of radon and other internally deposited alpha-emitters. Washington, DC: Nainternally deposited alpha-em

17 McDonald JC, Liddell FDK, Gibbs GW, Eyssen GE, McDonald AD. Dust exposure and mortality in chrysotile mining, 1910-75. Br f Ind Med 1980;37:1 1-24.

18 Dunnigan J. Linking chrysotile asbestos with mesothelioma. Am $\mathcal{F}$ Ind Med 1988;14:205-9.

19 Peto J. Fibre carcinogenesis and environmental hazards. In Bigon J, Peto J, Saracci R, eds. Non-occupational exposure to mineral fibres. Lyon: International Agency for Research on mineral fibres. Lyon: In

20 Browne $\mathrm{K}$. A threshold for asbestos related lung cancer. $\mathrm{Br}$ f Ind Med 1986;43:556-8.

21 Peto J, Doll R, Hermon C, Binns W, Clayton R, Goffe T. Relationship of mortality to measures of environmental asbestos pollution in an asbestos textile factory. Ann Occup Hyg 1985;29:1985.

22 Hammond EC, Selikoff IJ, Seidman $\mathrm{H}$. Asbestos exposure, cigarette smoking and death rates. Ann N Y Acad Sci 1979; 330;473-90.

23 Berry G, Newhouse ML, Antonis P. Combined effects of asbestos and smoking on mortality from lung cancer and mesothelioma. Br F Ind Med 1985;42:12-8.

24 Selikoff IJ. Use of death certificates in epidemiological studies, including occupational hazards: discordance with clinical and autopsy findings. Am $\mathcal{F}$ Ind $M e d$ 22:469-80.

25 Sebastien P, McDonald JC, McDonald AD, Case B, Harley R. Respiratory cancer in chrysotile textile and mining industries: exposure inferences from lung analysis. $\operatorname{Br} \mathcal{F}$ Ind industries: exposure

26 Tolbert PE, Eisen EA, Pottier L, Monson RR, Hallock MF, Smith TJ. Mortality studies of machining fluid exposure in the automobile industry II. Risks associated with specific fluid types. Scand $\Im$ Work Environ Health 1992;18:351-60.

27 Stanton MF, Layard M, Tegeris A, Miller E, May M, Morgan $\mathrm{E}$, Smith A. Relation of particle dimension to carcinogenecity in amphibole asbestos and other fibrous minerals. Ұ Natl Cancer Inst 1981;67:965-75. 